\title{
Language Contact: A Study of Syllabic Change of English Borrowed Words in Urdu
}

\author{
Shereen Ahmed $^{1}$, Behzad Anwar ${ }^{1} \&$ Tabassum Iqbal $^{1}$ \\ ${ }^{1}$ Department of English, University of Gujrat, Gujrat, Pakistan \\ Correspondence: Tabassum Iqbal, Department of English, University of Gujrat, Gujrat. E-mail: \\ tabassum.iqbal@uog.edu.pk
}

Received: November 11, 2017 Accepted: December 2, 2017 Online Published: December 23, 2017

doi:10.5539/ijel.v8n2p140 URL: http://doi.org/10.5539/ijel.v8n2p140

\begin{abstract}
This paper aims to describe the syllabic changes in those words which Urdu has borrowed from the English language. The changes are observed by exploring the sequence of sounds present in the syllables of English words. The results are presented on the basis of collection of English words taken from Urdu lexicon. The syllable templates that undergo change during the process of Urdu syllabification are: CCV, CVC, CVCC, CCVC, CCVCC, CVVC, CVVVC, CCCV, CCCVC, and CCCVCC. The current study has formulated some specific generalizations and constraints on the basis of which these changes occur. The study has deduced two processes of epenthesis and replacement/substitution which trigger these changes with respect to the phonological rules and phonotactic constraints of the Urdu language.
\end{abstract}

Keywords: syllabic change, English borrowing, phonotactic constraints, syllabic templates

\section{Introduction}

In the phonology of any language syllables play a vital role to understand the phonological formation and grammar of the language. Every language comprises its own particular rules of syllabification that are applied to modify the structure of borrowed words according to phonological rules of these specific languages (Hays, 2009). The Urdu language is one of those languages which undergo the syllabic changes when they borrow words from other languages. Urdu is allied with the new Indo-Aryan languages and is the national and official language of Pakistan. It is spoken in more than ten countries by about 591,000,000 people either as their mother tongue or second language (Wyne, 2002). Like other languages, it has the capacity to absorb different words from other languages. It has borrowed numerous words from other languages to enlarge its vocabulary. English is one of those languages which affected Urdu in a number of ways.

Today, English borrowed words have become the part of Urdu lexicon after undergoing the process of re-syllabification. As other languages impose some phonological restrictions on the syllabification of borrowed words, Urdu is no exception. Both English and Urdu contain different syllabic patterns and follow variant phonotactic rules to construct the syllabic structure of different words.

The present study aims at investigating the syllabic changes occurred in English borrowed words when they become the part of the Urdu language due to the influence of Urdu phonological principles. No significant research has been carried out on the phenomenon of syllabification in the Urdu language with respect to English borrowed words. So this study is an attempt to explore these changes occurred in the English borrowed words. In this study the syllabic changes are studied, showing various restrictions with respect to the phonotactic constraints and the phonological rules of Urdu that are imposed on making these changes.

\subsection{Research Questions}

This study aims to answer the following questions:

1) How can the English words change their syllabic structure and where these changes occur within the syllable of English borrowed words?

2) How can the syllabic variations in English borrowed words affect the number of syllables found in these words?

3) Which English syllabic templates change during the process of syllabification? 


\section{Literature Review}

As the present study deals with the phenomenon of syllabification in the Urdu language, so before exploring the syllabic changes occurred in English borrowed words, it is important to discuss some important concepts related to the study. The basic things required to comprehend this phenomenon are; the concept of syllables, the internal structure of syllable, its basic parts and the concept of syllabification.

\subsection{Syllable}

In the earlier studies of linguistics, the notion of syllable did not get any serious attention or important recognition. But through the subsequent researches of modern phonologists the direction of this idea changed and now it is considered a very important phonological entity in understanding the internal structure of words. (Kenstowicz, 1994). According to Ladefoged (2000) every person can identify the number of syllable present in a word, but to define the syllable is not an easy task. According to him, syllable is a basic unit of speech. It is the ability of human attitude which breaks speech into its minimal units. Syllables are phonological entities that comprise a string of phonemes (Marchand et al., 2009). Kenstowicz (1994) treats syllable as a specific idea which tell us the actual phonological construction of words. Hayes (2009) defines syllable as "stress bearing unit". Trask (1996) has presented some theories to describe the syllable. According to him the syllable can be defined in three ways; in terms of muscular activities, in terms of the peaks of sonority and according to the movement of chest pulses made during the utterance of each syllable.

\subsection{Syllable Structure}

The structure of the syllable got much attention over the last few decades. The earlier studies have found that the understanding of the syllable structure is necessary to know the phonological features of a language. Trask (1996) has claimed that the division of syllable is natural in every language. He divided the syllable into two major segments: onset and rhyme. Rhyme is further broken into two parts that are nucleus and coda.

\subsubsection{Onset}

Onset is the part of a syllable that comes before rhyme. Hayes (2009) described onset as the initial component of a syllable which contains either one consonant or group of consonants. There can be zero, one or more than one consonants in the onset position (Goldsmith, 1990).

\subsubsection{Nucleus}

The nucleus is the second and middle part of the syllable that follows onset and precedes coda. Every syllable has at least one nucleus in it. It is the indispensable component of a syllable and has got a special status in the syllable structure of a word. According to Ladefoged (2002) a vowel or a diphthong can come in the nucleus position of the syllable but in some cases vocalic part may occupy this position.

\subsubsection{Coda}

Coda is the last component of syllable and it appears after vowel sound. Like onset this slot may be filled with zero, one or more than one consonant. The omission of onset and coda within the syllable does not disturb the syllable organization, but the loss of the nucleus disturbs the whole syllable structure and also effects the location of stress and tone (Kenstowicz, 1994). Every language imposes its restrictions on the occurrence of sounds in these segments of the syllable (Goldsmith, 1990, p. 108).

Jensen (1993) described the internal syllable structure of the English language. According to him the English language has complex structure of syllable and can allow the complex combination of consonants in both onset and coda position of the syllable. However, coda consonants occur only at the word's internal position. He has illustrated this concept of occurrence of consonant sounds for both onset and coda positions in following tree diagram. 


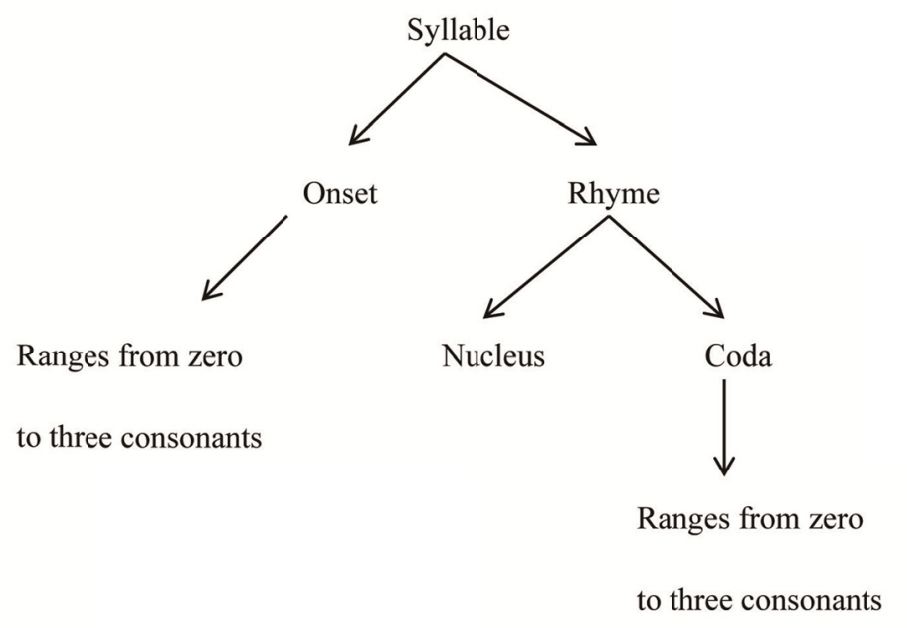

(Jensen, 1993)

Figure 1. English syllable structure

But the syllabic structure of the Urdu language does not match with English syllabic structure. In Urdu only one consonant can come in onset position and it allows maximum two consonants in coda position (Akram, 2002). According to the English phonology the nucleus of a syllable may carry both vocalic and non-vocalic sounds in its position (Ladefoged, 2002). But in the Urdu language the appearance of non-vocalic sounds are not permitted in the nucleus position of the syllable of a word (Bokhari \& Pervez, 2003). Both Urdu and English languages comprise variant phonological rules and syllabic templates to syllabify the words. The possible syllabic templates of Urdu and English language are:

English syllable templates

\section{$\mathrm{V}, \mathrm{CV}, \mathrm{CCV}, \mathrm{CCCV}, \mathrm{VC}, \mathrm{VCC}, \mathrm{VCCC}, \mathrm{CVC}, \mathrm{CVCC}, \mathrm{CVCCC}, \mathrm{CVCCCC}, \mathrm{CCVC}, \mathrm{CCVCC}, \mathrm{CCVCCC}, \mathrm{CCCVC}, \mathrm{CCCV}$ CC,CCCVCCC (Cox et al., 2009).}

Urdu syllable templates

V,VV,VC,CV,VCC,VVC,CVC,CVV,CVCC,CVVC,CVVCC (Usman et al., 2002).

In case of syllabifying the borrowed words, both languages follow different rules to divide the words into their minimal segments and create a different syllabic structure of these borrowed words.

\subsection{Syllabification}

Syllabification has a special significance in the field of linguistics and performs a vital role in the production of speech and speech recognition (Kiraz \& Mobius, 1998). Bartlett et al. (2009) treat syllabification as an analytical procedure which breaks a syllable into its smallest constituents. Goldsmith (1990) argues that syllabification is a process that makes different segments of a word in a linear order to organize the syllabic structure of the word. Krenn (1997) gave a different idea in which he treats syllabification as a tagging task. She prepared tags for each phone and recovered the syllable boundaries by putting these tags.

The Urdu language comprises rich phonology and has its own method of syllabification. The previous researches identified the syllable templates existing in the Urdu language but not appropriate description was given to understand the syllabification rules of the Urdu language especially with respect to the borrowed words the Urdu language taken from the English language. So the present study is an attempt to explore the process of syllabification in the English words used in the Urdu language and to explore the changes that are made during this process.

\section{Methodology and Data Collection}

The present research is qualitative and exploratory in nature. As the aim of this study is to analyze the syllabic changes of English borrowed words in the Urdu language, so the qualitative research was more appropriate for this study because through the use of this approach the changes will be examined by exploring the contextual behavior of the Urdu speakers that how the words are actually pronounced by the speakers in the real context of the Urdu language. In order to judge the syllabic changes in English borrowed words the data of English words 
has been collected in a very systematic way by using Jadeed Naseem Al-lughat Urdu and Oxford Urdu English Lughat. A dictionary of phonetics and phonology and a first dictionary of linguistics and phonetics (6th edition) were consulted for validation. The selection of Urdu lexicon to collect data was necessary for the confirmation of the idea whether these English words are the part of both English and Urdu languages or not.

English words were pronounced by the Urdu speakers to check the correct Urdu syllabification of these borrowed words. Before distributing the data among Urdu speakers the data was arranged into Urdu phrases to remove the element of consciousness in the speech of native Urdu speakers. The researchers chose purposive sampling technique to select the native speakers of Urdu because it establishes an excellent correspondence between the population and the research questions (Bryman, 2004). 40 native speakers of Urdu from Bhimber district of Azad Jammu and Kashmir were selected for this study on the basis of their knowledge and understanding of both languages.

The speech of each and every speaker was recorded for the purpose of transcribing the data. For recording a separate room was chosen to avoid the interruption of other voices and to have a better quality of sound. A specific software 'Praat' has been used to get the clear and authentic transcription of the collected data. Then by comparing the Urdu syllabification with actual syllabification of English words the changes were examined that occurred due to the effect of Urdu phonological rules.

\section{Results and Discussion}

The changes in the syllabic structure of English borrowed words have been explored by determining the change occurring in the sequence of vowel and consonant sounds in different positions of the syllable of the words and also by examining the processes that disturb the internal structure of the syllable of a word. The study has found the occurrence of the processes of epenthesis (insertion of sounds) and substitution of sounds as the main cause of syllabic changes. Different templates of English words that undergo the syllabic change due to these two processes are also highlighted in the study.

\subsection{Insertion of Sound between the Initial Onset Consonant Clusters}

This aspect discusses the syllabic change occurred in the onset position when some consonant clusters appeared in the onset position of the syllable of a word. The changes in this position have been noticed under certain conditions.

\subsubsection{Condition 1}

According to this case if the syllable of an English word contains two consonants cluster in the initial onset position and the first consonant is associated with the category of stops $(/ \mathrm{p} /, / \mathrm{b} /, / \mathrm{t} /, / \mathrm{d} /, / \mathrm{k} /, / \mathrm{g} /)$ while the second consonant is the member of the set of liquids $(/ 1 /, / \mathrm{r} /)$ then Urdu speakers insert $/ \mathrm{a} /$ central vowel between this consonant cluster to simplify it. And this simplification of two consonants changes the syllabic structure of English words. The study has identified some consonant clusters that are broken apart by this insertion process that are: /pr/, /pl/, /bl/, /br/, /tr/, /dr/, /kl/, /kr/, /gr/, /gl/. The syllabic templates changed due to this insertion are $\mathrm{CCV}, \mathrm{CCVC}$, and CCVCC. The changes in the three templates can be observed in the below given examples.

\begin{tabular}{lll}
\hline English Words & English Syllabification & Urdu Syllabification \\
\hline Glue & /glu:/(CCV) & /gə.lu:/ (CV.CV) \\
Class & /kla:s/ (CCVC) & /kə.la:s/(CV.CVC) \\
Branch & /bra:ntf/(CCVCC) & /bə.ra:nt $/$ (CV.CVCC) \\
\hline
\end{tabular}

\subsubsection{Condition 2}

According to this condition if two consonant comes in the word's initial onset position and the initial consonant belongs to the class of fricatives $(/ \mathrm{f} /, / \mathrm{s} /, / \theta /)$ while the following consonant is linked with the category of liquids $(/ 1 /, / r /)$ then Urdu speakers simplify this cluster by adding /a/ vowel between them which alter the syllabic structure of the word. The consonant clusters affected by this insertion process are: /fl/, /fr/, /sl/, / $\theta \mathrm{r} /$. The syllabic templates changed under this condition are same as observed in the previous case and these are: $\mathrm{CCVC}, \mathrm{CCV}$ and CCVCC.

\begin{tabular}{lll}
\hline English Words & English Syllabification & Urdu Syllabification \\
\hline Flue & /flu:/ (CCV) & /fəlu:/ (CVCV) \\
Slip & /slip/ (CCVC) & /sə.lip/ (CV.CVC) \\
Front & /frsnt/ (CCVCC) & /fərənt/ (CV.CVCC) \\
\hline
\end{tabular}




\subsubsection{Condition 3}

This case describes the syllabic change occurred due to the existence of three consonants cluster in the onset position of the syllable of a word. According to this case, if three consonants cluster appear in the onset position and the first consonant is fricative /s/ that is preceding the consonant associated with one of the two stops (/p/, $/ \mathrm{t} /)$ then Urdu speakers make the insertion of /a/ vowel between the two initial consonants without disturbing the last member of this consonants cluster due to which the syllabic structure of the word changes. The analysed patterns of these consonants clusters that are simplified by this process are: /spl/, /spr/, /skr/,/skw/. The syllabic templates changed due to this type of vowel insertion are CCCV, CCCVC and CCCVCC.

\begin{tabular}{lll}
\hline English Words & English Syllabification & Urdu Syllabification \\
Screw & /sk.ru:/ (CCCV) & /sək.ru:/ (CVC.CV) \\
Spring & /sprin/ (CCCVC) & /səp.rin/ (CVC.CVC) \\
Script & /skript/ (CCCVCC) & /sək.ript/ (CVC.CVCC) \\
\hline
\end{tabular}

\subsection{Insertion of Sound between Final Coda Consonant Clusters}

In the coda position the epenthesis process is performed in two ways. First the insertion of sound is done to simplify the final consonants cluster. Secondly the insertion of sound is done in the coda position to produce the consonants cluster in the word's final position. The way of inserting sounds in two situations is different but both alter the syllabic structure of the word.

\subsubsection{Condition 1}

This case describes syllabic change that occurred due to the simplification of final consonants cluster. According to this case if two consonants appear in the word's final coda position and the first consonant in this consonant cluster is liquid / $/$ then Urdu speakers insert /a/ vowel between this cluster to simplify it due to which the change occurs in the syllable structure of the word. The consonant clusters that are simplified by the insertion of /a/ vowel are: $/ \mathrm{lb} /, / 1 \mathrm{f} /, / \mathrm{k} /, / \mathrm{lm} /$. The study has analyzed various words with CVCC syllabic structure that change their shape during this insertion process.

\begin{tabular}{lll}
$\longrightarrow$ & CVCC & CV.CVC \\
\hline English words & English syllabification & Urdu syllabification \\
\hline Bulb & $/ \mathrm{b} \Lambda \mathrm{lb} /$ & $/ \mathrm{bo.ləb} /$ \\
Film & $/ \mathrm{frlm} /$ & $/ \mathrm{fr} . l \mathrm{~lm} /$ \\
Silk & $/ \mathrm{silk} /$ & $/$ sı.lək/ \\
\hline
\end{tabular}

\subsubsection{Condition 2}

This case discusses the syllabic change that occurred due to the insertion of consonant $/ \mathrm{r} /$ in the coda position just after the vowel sound to make the consonants cluster. According to syllabification of standard British English / $\mathrm{r}$ / consonant can never come just after the vowel sound but only comes before the vowel sound in the onset position. But in Urdu the case is different from that of English. Urdu speakers allow the insertion of $/ \mathrm{r} /$ dchanges. The study has noticed this change in the different English words with CVC syllabic structure. The following examples illustrate this process.

\begin{tabular}{lll}
$\longrightarrow$ & \multicolumn{1}{c}{ CVC } & CVCC \\
\hline English words & English syllabification & Urdu syllabification \\
\hline Card & $/ \mathrm{ka}: \mathrm{d} /$ & $/ \mathrm{ka}: \mathrm{rd} /$ \\
Charge & $/ \mathrm{t} \mathrm{fa}: \mathrm{d} /$ & $/ \mathrm{t} \mathrm{fa}: \mathrm{rd} /$ \\
Park & $/ \mathrm{pa}: \mathrm{k} /$ & $/ \mathrm{pa}: \mathrm{rk} /$ \\
\hline
\end{tabular}

\subsection{Replacement of Sounds in Nucleus Position}

This case describes the syllabic change occurred due to the replacement of some vowel sounds in the nucleus position of the English words.

According to the English phonological rules both vocalic and non-vocalic sounds may occupy the position of nucleus (Ladefoged, 2002). But Urdu does not permit non- vocalic sounds as the nucleus of the syllable of a word (Bokhari \& Pervez, 2003). Similarly, both languages have some restrictions on the existence of theses vocalic sounds in the nucleus position of the syllable of a word. In English there is a possibility of appearing all 
kind of vowel sounds, (monophthongs, diphthongs, or triphthongs) as the nucleus of the word but in Urdu the occurrence of these sounds in nucleus position is restricted. So when the English words come in Urdu then the replacement of different sounds occurs in the nucleus position due to which the syllabic structure of the word changes.

\subsubsection{Replacement of Diphthongs}

The study has identified only two kinds of diphthongs (/əv/, /ei/) that undergo the process of replacement to change the syllabic structure of the English words. The diphthong/əv/ is replaced with long vowel /o:/ and the diphthong /ei/ is replaced with long vowel /e:/. All the words changed during this replacement process contain CVVC syllabic structure.

\begin{tabular}{lll}
$\longrightarrow$ & CVVC & CVC \\
\hline English Words & English syllabification & Urdu syllabification \\
\hline Coat & $/$ kəot/ & /ko:t/ \\
Road & $/$ rəod/ & $/$ ro:d/ \\
Gate & $/$ gert/ & $/$ ge:t/ \\
Weight & $/$ wert/ & $/$ we:t/ \\
\hline
\end{tabular}

\subsubsection{Replacement of Triphthong}

This case describes the syllabic change occurred due to the replacement of triphthong in the middle position of the syllable. According to this case if an English word contains the triphthong /ava/ as its nucleus in the middle of the word then Urdu speakers replace the middle member of the triphthong with the glide consonant $/ \mathrm{w} /$ and then shift this consonant to the onset of the next syllable due to which the syllable is broken into two segments and the structure of the syllable changes. The English syllabic template disturbed due to this replacement process is CVVVC templates.

\begin{tabular}{lll}
$\longrightarrow$ & CVVVC & CV.CVC \\
\hline English Words & English syllabification & Urdu syllabification \\
\hline Power & /paoər/ & /pa.wər/ \\
Tower & /tavər/ & /ta.wər/ \\
\hline
\end{tabular}

\section{Conclusion}

The present study has revealed that English words undergo certain syllabic changes when they are used in the Urdu language due to the adaptation of variant phonological rules of Urdu. The study has explored the processes of Epenthesis and replacement which change the phenomenon of syllabification. This study attempted to describe the rules and restrictions that Urdu imposes in constructing the syllabic structure of English borrowed words. The study has extracted the following templates which change during the process of Urdu syllabification along with some other aspects explored in this study:

\begin{tabular}{|c|c|}
\hline CCVC & CV.CVC (Onset stop + liquid) or (Onset fricative + liquid $)$ \\
\hline $\mathrm{CCV}$ & CV.CV (Onset stop + liquid) or (Onset fricative + liquid) \\
\hline CCVCC & CV.CVCC (Onset stop + liquid) or (Onset fricative + liquid) \\
\hline $\mathrm{CCCV}$ & CVC.CV (Onset fricative + stop + any category) \\
\hline CCCVC & CVC.CVC (Onset fricative + stop + any category) \\
\hline CCCVCC & CVC.CVCC (Onset fricative + stop + any category) \\
\hline $\mathrm{CVC}$ & CV.CV (insertion of $r$ in coda position) \\
\hline CVCC & CV.CVC (coda liquid + any category) \\
\hline CVVC & CVC (diphthongs in the nucleus) \\
\hline VVVC & CV.CVC (triphthongs in the nucleus) \\
\hline
\end{tabular}




\section{References}

Akram, B. (2002). Analysis of Urdu Syllabification Using Maximal Onset Principle and Sonority Sequence Principle. Centre for Research in Urdu Language Processing, 1, 160-166. National University of Computer and Emerging Sciences, Lahore, Pakistan.

Bartlett, S., Kondrak, G., \& Cherry, C. (2009). On the Syllabification of Phonemes. Paper Presented at the Proceeding of Human Language Technologies: The 2009 Annual Conference of the North American Chapter of the Association of the Computational Linguistics, 308-316. Boulder, Colorado, USA. Association for Computational Linguistics. https://doi.org/10.3115/1620754.1620799

Bokhari, R., \& Pervez, S. (2003). Syllabification and Resyllabification in Urdu. Akhbar-i-Urdu (pp. 63-67). Lahore, Pakistan.

Bryman, A. (2004). Social Research Methods (2nd ed.). Oxford: Oxford University Press.

Cox, F., Harrington, J., \& Mannell, R. (2009). Phonetics and Phonology, The Syllable: Introduction. Macquarie University Press. Retrieved from http://clas.mq.edu.au/Phonetics/Phonology/Syllable/Syll-introduction-html

Goldsmith, J. A. (1990). Autosegmental and Metrical Phonology. Oxford: Blackwell.

Hayes, B. (2009). Introductory Phonology. Chichester: Blackwell.

Jadeed Naseem Alughat Urdu. (1989). Lahore: Sheikh Ghulam Ali \& Sons Ltd Publishers.

Jensen, J. T. (1993). English phonology (pp. 47-76). Amsterdam: John Benjamin Publishing Company. https://doi.org/10.1075/cilt.99

Kenstowicz, M. J. (1994). Phonology in Generative Grammar. Oxford: Blackwell Publications.

Kiraz, G., \& Mobius, B. (1998). Multilingual Syllabification Using Weighted Finite-state transducers. In Proceedings of the 3rd Workshop on Speech Synthesis, 59-64.

Krenn, B. (1997). Tagging Syllables. In Proceedings of the 5th European Conference on Speech Communication and Technology, Euro Speech, 97, 991-994.

Ladefoged, P. (2000). A Course in Phonetics (4th ed.). USA: Thomson Publications.

Marchand, Y., Adsett, C \& Damper, R. (2009). Automatic Syllabification in English: A Comparison of Different Algorithms. Language and Speech, 52, 1-27. https://doi.org/10.1177/0023830908099881

Oxford Urdu English Lughat. (2013). Pakistan: Oxford University Press.

Trask, R. L. (1996). A Dictionary of Phonetic and Phonology. London: Taylor \& Francis Routledge.

Usman, M., Ali, S. F., \& Masood, A. (2002). Syllabification of English Words in Urdu. Annual Report of Centre for Research in Urdu Language Processing (CRULP). National University of Computer and Emerging Sciences, Lahore, Pakistan.

Wyne, N. (2002). Language and the Families. Center for Research in Urdu Language Processing (CRULP). National University of Computer and Emerging Sciences, Lahore, Pakistan.

\section{Appendix}

\begin{tabular}{|c|c|c|}
\hline English words & English Syllabification & Urdu Syllabification \\
\hline Glue & /glu:/ & /gə.lu:/ \\
\hline Glass & /gla:s/ & /gə.la:s/ \\
\hline Block & /blvk/ & /bo.lvk/ \\
\hline Graph & /gra:f/ & /gə.ra:f/ \\
\hline Clean & /kli:n/ & /kə.li:n/ \\
\hline Drum & $/ \mathrm{dr} \Lambda \mathrm{m} /$ & /də.r $\Lambda \mathrm{m} /$ \\
\hline Proof & /pru:f/ & /pə.ru:f/ \\
\hline Plug & /plng/ & $/ \mathrm{p} \curvearrowright .1 \Lambda \mathrm{g} /$ \\
\hline Grant & /gra:nt/ & /gə.ra:nt/ \\
\hline Print & /print/ & /pə.rınt/ \\
\hline Free & /fri:/ & /fə.ri:/ \\
\hline Fruit & /fru:t/ & /fə.ru:t/ \\
\hline Frock & /fro:k/ & /fə.rp:k/ \\
\hline
\end{tabular}




\begin{tabular}{|c|c|c|}
\hline Friend & /frend/ & /fə.rend/ \\
\hline Screen & /sək.ri:n/ & /sək.ri:n/ \\
\hline Script & /skript/ & /sək.ript/ \\
\hline Squash & /skwo:f/ & /sək.wp:f/ \\
\hline Milk & $/ \mathrm{mIlk} /$ & /mI.lək/ \\
\hline Silk & /silk/ & /sI.lək/ \\
\hline Card & /ka:d/ & /ka:rd/ \\
\hline Guard & /ga:d/ & /ga:rd/ \\
\hline March & /ma:tf/ & /ma:rtf/ \\
\hline Shark & / $\mathrm{a}: \mathrm{k} /$ & / $\mathrm{a} a: r k /$ \\
\hline Board & /bo:d/ & /bo:rd/ \\
\hline Course & /ko:s/ & /ko:rs/ \\
\hline Shirt & $/ \sqrt{3}: t /$ & / ฮə:rt/ \\
\hline Girl & /g3:1/ & gə:rl/ \\
\hline Code & /kəud/ & /ko:d/ \\
\hline Coach & /kəut $\mathrm{f} /$ & /ko:tj/ \\
\hline Load & /ləud/ & /lo:d/ \\
\hline Note & /nəut/ & /no:t/ \\
\hline Fail & /ferl/ & /fe:1/ \\
\hline Tape & /terp/ & /te:p/ \\
\hline Jail & /dzerl/ & /dze:1/ \\
\hline Sale & $/$ serll/ & /se:1/ \\
\hline Power & /pavər/ & Pa.wər/ \\
\hline Tower & /taoər/ & ta.wər/ \\
\hline
\end{tabular}

\section{Copyrights}

Copyright for this article is retained by the author(s), with first publication rights granted to the journal.

This is an open-access article distributed under the terms and conditions of the Creative Commons Attribution license (http://creativecommons.org/licenses/by/4.0/). 